\title{
Elastic bandage vs. neoprene thumb stabilizer splint in acute De Quervain's tenosynovitis
}

\author{
Hathaya Jongprasitkul ${ }^{\mathrm{a}}$, Areerat Suputtitada ${ }^{\mathrm{a}}$, Wasuwat Kitisomprayoonkul ${ }^{\mathrm{a}}$, Kruawan Pintawiruj ${ }^{\mathrm{b}}$ \\ ${ }^{a}$ Department of Rehabilitation Medicine, Faculty of Medicine, Chulalongkorn University, ${ }^{b}$ Division of \\ Rehabilitation Medicine, King Chulalongkorn Memorial Hospital, Bangkok 10330, Thailand
}

\begin{abstract}
Background: De Quervain's tenosynovitis is a common disease among the patients who performed unaccustomed repetitive movement of the thumb side of the wrist. A neoprene thumb stabilizer splint is often used to restrict thumb movement. However, because of its cost, usage of an elastic bandage made of cheaper materials is proposed.

Objective: Compare the effectiveness between the elastic bandage and the neoprene thumb stabilizer splint in acute De Quervain's tenosynovitis.

Methods: Forty participants with acute De Quervain's tenosynovitis were divided into two groups (20 participants each). The first group used the elastic bandage, and the second group used the neoprene thumb stabilizer splint. Visual Analog Scale (VAS) pain, lateral and palmar pinch strength were measured before and after using the bandage and the splint for one or two weeks.

Results: The average ages in the bandage and the splint group were $53.15 \pm 10.42$ and $48 \pm 11.7$ years, respectively. The VAS pain score of the bandage and splint group over week 0, 1, and 2 were 58.50, 33.90 and 19.55, and 51.60, 35.85 and 25.20, respectively. The bandage and splint group had the lateral pinch strength over the time of 9.40 , 10.70 and $11.25 \mathrm{lbs}$, and 8.90, 9.88 and $10.57 \mathrm{lbs}$, respectively. Furthermore, they had the palmar pinch strength of 3.63, 4.68 and $5.28 \mathrm{lbs}$, and 3.07, 3.92 and $4.29 \mathrm{lbs}$, respectively.

Conclusion: The pain and strength were not significantly different between the bandage and the splint group in acute De Quervain tenosynovitis. Using the bandage may be more cost-effectiveness than using the splint.
\end{abstract}

Keywords: Acute De Quervain’s tenosynovitis, elastic bandage, pinch strength, thumb stabilizer splint, visual analog scale

De Quervain's tenosynovitis is an inflammation of synovium retinacular sheath and tendon of extensor pollicis brevis (EPB) and abductor pollicis longus (APL) at the wrist [1-3]. A major cause of the disease is repetitive stretching of thumb abductor and tilting wrist towards the ulnar side [1, 2].

Another cause might be acute injuries [1]. The patients have a radial wrist pain that spreads farther to the thumb or back into the forearm. Grasping and thumb movements aggravate the pain. Tenderness at the radial wrist is observed, sometimes with swelling at the wrist. The Finkelstein's test provides a positive indicator of the disease [1-4].

Correspondence to: Hathaya Jongprasitkul, OT, Occupational Therapy Unit, Department of Rehabilitation Medicine, Faculty of Medicine, Chulalongkorn University, Bangkok 10330, Thailand.E-mail: rhnc123@truemail.co.th
Treatments of the disease consist of medication and non-medication. The non-medication includes immobilization, therapeutic heat and cold, electrical nerve stimulator, thumb stabilizer splint, postural correction at work, and the adjustment of tools and equipment [5-8]. The medication included NonSteroidal Anti-Inflammatory Drugs (NSAIDs) and analgesic, an injection of a steroid mixed with xylocaine into tendons sheaths. Decompression of the first dorsal compartment demonstrated a good result, but surgery is rarely made except if the patient does not respond well to those treatments $[1,2]$.

The thumb stabilizer splint decreases movement of the wrist and the thumb [1-4]. In Thailand, two types of the splint are commonly used. The first type is a custom-made thermoplastic thumb stabilizer splint (cost: 400-500 Thai baht), which is too rigid for patient 
having inflammation as a cause of pain. Its advantage is well-fitting for each patient. The second type is an imported prefabricated neoprene (cost: 300-400 Thai baht), which is more flexible than the first type. Its disadvantage is that it is not well-fitting and sometimes the patients get eczema or dermatitis caused by neoprene.

Because of the government expenditures for personal health care, another way to use an elastic bandage from cheaper materials is proposed. The elastic bandage wrap is made from local materials, and used to support an injured area. It can decrease pain, and reduce swelling of an injured area [9]. In addition, it is easily available in drug store or convenience store with the cost of only 10-20 baht per roll. However, few data are available on applicability of the elastic bandage in basic treatment of hand injury. In this study, we compared the effectiveness between the elastic bandage and the neoprene thumb stabilizer splint in acute De Quervain's tenosynovitis.

\section{Materials and methods}

This study was approved by the Research Ethics Committee of the Faculty of Medicine, Chulalongkorn University. Forty patients with acute De Quervain's tenosynovitis have a positive Finkelstein's test (pain with the thumb in the palm and ulnar deviation of the wrist) aged above 18 years, were recruited at King Chulalongkorn Memorial Hospital. Informed consent forms were explained to the patients, and they voluntarily agreed to participate. Exclusion criteria of the participants were: 1 ) orthopedic diseases of wrist and hand (e.g. rheumatoid arthritis), 2) osteoarthritis and other types of arthritis, and 3) received steroid injection of De Quervain's tenosynovitis within three months.

The materials for this study included 1) Jamar ${ }^{\circledR}$ Hydrulic Pinch Gauge (Sammons Preston Rolyan A Patterson Medical Co, Bolingbrook, USA). 2) elastic bandage of two to three inches sized, and, 3) Oppo ${ }^{\circledR}$ Wrist and thumb stabilizer (Oppo Medical Inc, Seattle, USA).The participants characteristics were recorded. Perception of pain during performing daily tasks was measured using Visual Analog Scale (VAS). Lateral and palmar pinch strength was also measured using Jamar ${ }^{\circledR}$ Hydrulic Pinch Gauge [10].

The participants were randomly divided into two groups. The first group of 20 participants received wrapped elastic bandage. Starting to wrap the bandage around a palm twice, the next step was to bind the base of the thumb two times, continue wrapping around the palm again, pull down bandage across the back of the hand, and wrap the bandage throughout the wrist two times. The loose end of the bandage was fastened with bandage clips or medical tape. If the hand looked pale or cold, the bandage was wrapped too tightly. It was removed, and rewrapped again, as shown in Figure. 1. The second group of 20 participants wore neoprene thumb stabilizer splint as shown in Figure. 2. Both groups used splint or bandage at least six hours per day for two weeks. They did not receive any anti-inflammatory medication and analgesics. The patients were blindly assessed using the VAS pain scale, the lateral, and palmar pinch strength gauge, and the patient's satisfaction scale before and after using the bandage and the splint at end of the first and the second week.
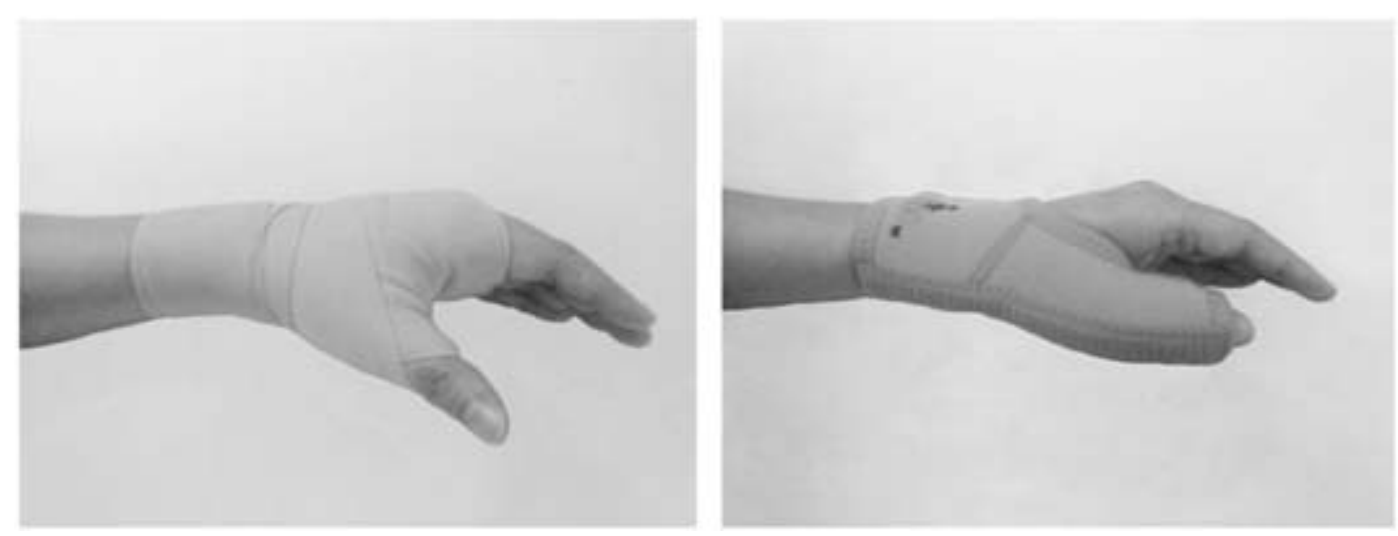

Figure 1. Wrapping of elastic bandage (A) and neoprene thumb stabilizer (B). 


\section{Data analysis}

The participant characteristics were presented in Table 1.

The VAS score and the lateral and palmar pinch strength, in either the bandage group or the splint group were compared over the time using the Friedman test. The same variables of both groups at the time were compared using the Mann-Whitney U test and the statistical level of significance was 95\% and 99\%

\section{Results}

The bandage group was $53.15 \pm 10.42$ years of age, while the splint group was $48 \pm 11.7$ years of age. Most participants in both groups were female (90\% for the former group: 95\% for the splint group). Participants had symptom for $3.4 \pm 2.28$ weeks in the former group and $3.55 \pm 1.93$ weeks in the splint group
(Table 1).

The splint group had statistically reduced pain and increased strength after one and two weeks ( $\mathrm{p}<$ 0.001) as shown in Table 2.

Table 3 shows pain level by VAS, lateral and palmar pinch strength before and after using elastic bandage. Interestingly, the bandage group statistically reduced pain and increased strength after one and two weeks ( $\mathrm{p}<0.001)$.

Table 4 compares pain, lateral and palmar pinch strength after one and two weeks. There was no significant difference ( $p>0.05)$, when the variables of both groups were compared at the same period. However, the satisfaction score of the splint group was significant higher than the score of the bandage group $(\mathrm{p}<0.05)$.

Table 1. Characteristics of 40 participants.

\begin{tabular}{lll}
\hline Characteristics & $\begin{array}{l}\text { Elastic bandage } \\
(\mathbf{n = 2 0 )}\end{array}$ & $\begin{array}{l}\text { Neoprene thumb stabilizer splint } \\
\mathbf{( n = 2 0 )}\end{array}$ \\
\hline $\begin{array}{l}\text { Age } \\
\quad \text { Mean } \pm \text { SD (years) } \\
\begin{array}{c}\text { Gender } \\
\quad \text { Male, Number (\%) }\end{array}\end{array}$ & $53.15 \pm 10.42$ & $48.38 \pm 11.71$ \\
$\quad \begin{array}{l}\text { Female, Number (\%) } \\
\text { Duration of symptom } \\
\quad \text { Mean } \pm \text { SD (weeks) }\end{array}$ & $2(10 \%) 18(90 \%)$ & $1(5 \%) 19(95 \%)$ \\
\hline
\end{tabular}

Table 2. Comparison of pain level by VAS, lateral and palmar pinch strength before and after using the neoprene thumb stabilizer splint for 0,1 and 2 weeks.

\begin{tabular}{lllll}
\hline Variables & \multicolumn{3}{c}{ Mean \pm SD } & P-value \\
\cline { 2 - 4 } & Week 0 & Week 1 & Week 2 & \\
\hline VAS(100mm) & $51.60 \pm 12.42$ & $35.83 \pm 14.33$ & $25.20 \pm 14.16$ & $<0.001$ \\
Lateral pinch strength (lbs) & $8.90 \pm 2.73$ & $9.88 \pm 3.18$ & $10.57 \pm 2.48$ & $<0.001$ \\
Palmar pinch strength (lbs) & $3.07 \pm 1.33$ & $3.92 \pm 1.33$ & $4.29 \pm 1.36$ & $<0.001$ \\
\hline
\end{tabular}

Table 3. Comparison of pain level by VAS, lateral and palmar pinch strength before and after using elastic bandage for 0,1 and 2 weeks.

\begin{tabular}{lllll}
\hline Variables & \multicolumn{3}{c}{ Mean \pm SD } & P-value \\
\cline { 2 - 4 } & Week 0 & Week 1 & Week 2 & \\
\hline VAS(100mm) & $58.50 \pm 11.19$ & $33.80 \pm 10.71$ & $19.55 \pm 10.73$ & $<0.001$ \\
Lateral pinch strength (lbs) & $9.40 \pm 3.03$ & $10.70 \pm 3.88$ & $11.25 \pm 3.58$ & $<0.001$ \\
Palmar pinch strength (lbs) & $3.63 \pm 1.17$ & $4.68 \pm 1.45$ & $5.28 \pm 1.41$ & $<0.001$ \\
\hline
\end{tabular}


Table 4. Comparison of pain, lateral and palmar pinch strength.

\begin{tabular}{lcccc}
\hline Variables & Week & \multicolumn{2}{c}{ Mean \pm SD } & P-value \\
\cline { 3 - 4 } & & $\begin{array}{c}\text { Elastic bandage group } \\
\mathbf{( n = 2 0 )}\end{array}$ & $\begin{array}{c}\text { Neoprene thumb stabilizer } \\
\text { splint group (n=20) }\end{array}$ & \\
\hline VAS(100mm) & 1 & $33.80 \pm 10.71$ & $35.85 \pm 14.33$ & 0.551 \\
& 2 & $19.55 \pm 10.73$ & $25.20 \pm 14.16$ & 0.198 \\
Lateral pinch & 1 & $10.70 \pm 3.88$ & $9.88 \pm 3.18$ & 0.715 \\
strength (lbs) & 2 & $11.25 \pm 3.58$ & $10.57 \pm 2.48$ & 0.715 \\
Palmar pinch & 1 & $4.68 \pm 1.45$ & $3.92 \pm 1.33$ & 0.151 \\
strength (lbs) & 2 & $5.28 \pm 1.41$ & $4.29 \pm 1.36$ & 0.051 \\
\hline
\end{tabular}

Table 5. Comparison of satisfaction score between neoprene thumb stabilizer group and the elastic bandage group.

\begin{tabular}{lcc}
\hline $\begin{array}{c}\text { Mean } \pm \text { SD of Satisfaction score } \\
\begin{array}{c}\text { Elastic bandage group } \\
(\mathbf{n}=\mathbf{2 0})\end{array}\end{array}$ & $\begin{array}{c}\text { Peoprene thumb stabilizer splint group } \\
\mathbf{( n = 2 0 )}\end{array}$ & 0.013 \\
\hline $7.45 \pm 0.60$ & $7.90 \pm 0.45$ & \\
\hline
\end{tabular}

\section{Discussion}

This study has demonstrated that the elastic bandage can be substituted for the neoprene thumb splint in patients with acute De Quervain's tenosynovitis. There was no significant difference in the pain and strength between the bandage and the splint. According to Mckenzie [11] and Med [12], 90\% patients with acute De Quervain's tenosynovitis could be treated by wearing thumb spica splint for convenience and safety $[13,14]$. Splinting can be used particularly in the patients with mild symptom. Their alternative treatments are often applied to patients with NSAIDs. In those with moderate or severe symptom and using steroid injection, splinting with immobilization can be more effective [15-17]. Skoff [18] reported that those women with acute De Quervain's tenosynovitis after giving birth and bilateral involvement could be treated by splinting as a nonoperative treatment.

The present study attempted to reduce the cost of treatment by using elastic bandage wrap up to 40 times cheaper than the splint used. Importantly, the both materials produced similar results in pain reduction and strength improvement. However, the participants were satisfied with the splint rather than the bandage. This might be the inconvenient use of the elastic bandage, which is not ready-made. Therefore, this study suggests that elastic bandage wrap should be an important option for therapists. The patients must know both advantages and disadvantages of using the bandage instead of using the splint.

In conclusion, there was no significant difference of using the bandage and the splint in pain reduction and strength improvement in acute De Quervain's tenosynovitis.

\section{Acknowledgement}

This study was supported by Ratchadapiseksompotch Research Fund, Faculty of Medicine, Chulalongkorn University. The authors declare no conflict of interest.

\section{References}

1. Mackin EJ, Callahan AD, Skirven TM, Achneider LH, Osterman AL, Hunter JM. Rehabilitation of the hand and upper extreamity. 5th ed. St Louis: Mosby, 2002; p. 944-6.

2. Mooney V. Over use syndrome of the upper extremity, Rational and effective treatment. J Muscu Med. 1998; 15:11-8.

3. Verdon ME. Over use syndrome of the hand and wrist. Primary Care. 1996; 23: 305-19. 
4. Pascarelli EF, Kella JJ. Solf tissue injuries related to use of the computer. J Occup Med. 1993; 35:522-32.

5. Pedretti LW, Zolthan B. Occupational therapy practice skill for physical dysfunctional 3rd ed. St.Louis: CVMosby; 1990; p. 497-501.

6. Idler RS. Helping the patient who has wrist or hand tenosynovitis. J Muscu Med.1997; 14:21-35.

7. Johnson SL. Therapy of the occupational injured hand and upper extremity. Hand Clin. 1993; 9:2889-98.

8. Trombly CA, Radomski MV. Occupational therapy for physical dysfunction. 5th ed. Philadelphia Lappincott Williams \&Wilkins; 2002; p. 941.

9. Wikipedia, the free encyclopedia. [updated 2010 May 12; cited 2010 June 13]. Available from: http:// en.wikipedia.org/wiki/Elastic_bandage.

10. Pat L. Aulicino. Clinical examination of the hand. In: Hunter JM, Mackin EJ, Collahan AD, editors. Rehabilitation of the hand: Surgery and therapy 4 th ed. St Louis:Mosby, 1995; p. 65-6.

11. Mckenzie JM. Conservative treatment of De Quervain's disease. BMJ. 1972; 4:659.

12. Medl WT. Tedonitis, tenosynovitis, trigger finger and De Quervain’s disease. Orthop Clin North Am. 1970; 1:375.

13. Kirkpatrick W, Lisser S. Solf- tissue condition. In: Hunter JM, Mackin EJ, Collahan AD, editors. Rehabilitation of the hand: Surgery and therapy 4 th ed. St Louis:Mosby, 1995; p. 1013.

14. Hart RG, Kleinert HE, Lyons K. A modified thumb spica splint for thumb injuries in the ED. Am J Emerg Med. 2005; 23: 777-81.

15. I AsifM. Nonsurgical treatment for De Quervain's tenosynovitis. Hand Sur. 2009; 34A: 928-29.

16. Lane LB, Boretz RS, Stuchin SA. Treatment of De Quervain's tenosynovitis: role of conservative management. J Hand Sur. 2001; 73:258-60.

17. Witt J, Press G, Gelberman RH. Treatmemnt of De Quervain's tenosynovitis. A prospective study of the result of injection of steroids and immobilization insplint. J Bone Joint Sur. 1991; 73:219-22.

18. Skoff HD. Postpartum/newborn de Quervain's tenosynovitis of the wrist. Am J Orthop. 2001; 30: 428-30. 